\title{
Bestiários contemporâneos: animais na poesia brasileira e hispano-americana
}

\author{
Maria Esther Maciel \\ Universidade Federal de Minas Gerais
}

\begin{abstract}
RESUMO: ESTE ARTIGO ABORDA ALGUNS BESTIÁRIOS BRASILEIROS E HISPANO-AMERICANOS DA CONTEMPORANEIDADE - ESPECIALMENTE OS DE AUTORIA DE WILSON BUENO, AUGUSTO MONTERROSO E JUAN JOSÉ ARREOLA -, MOSTRANDO COMO ELES SUBVERTEM E REINVENTAM, POR VIAS IRÔNICAS, OS BESTIÁRIOS EUROPEUS DA IDADE MÉDIA E DO RENASCIMENTO. O ARTIGO TAMBÉM ANALISA DUAS VERTENTES DA CHAMADA ZOOLITERATURA: A DE VIÉS FANTÁSTICO E A DE FEIÇÃO REALISTA. O PROPÓSITO É DISCUTIR, POR MEIO DE UMA VISÃO CRÍTICA DA TRADIÇÃO ZOOLÓGICA OCIDENTAL, COMO OS ANIMAIS TÊM SIDO REPRESENTADOS NA POESIA E NA NARRATIVA CONTEMPORÂNEAS.
\end{abstract}

ABSTRACT: THIS PAPER FOCUSES ON SOME CONTEMPORARY BRAZILIAN AND LATIN AMERICAN BESTIARIES, SUCH AS THOSE WRITTEN BY WILSON BUENO, AUGUSTO MONTERROSO AND JUAN JOSÉ ARREOLA, SHOWING HOW THEY IRONICALLY SUBVERT AND REINVENT THE TRADITIONAL EUROPEAN BESTIARIES OF MIDDLE AGE AND RENAISSANCE. IT ALSO ANALYSES TWO TYPES OF THE SO-CALLED "ZOOLITERATURE" IN THE CONTEXT OF CONTEMPORARY CULTURE: THE ONE CHARACTERIZED BY FANTASTIC/IMAGINARY ROOTS AND THE ONE MARKED BY REALISTICAL AND ECOLOGICAL TRAITS. THE PURPOSE IS, THROUGH A CRITICAL VISION OF THE WESTERN ZOOLOGICAL TRADITIONS, TO DISCUSS HOW ANIMALS HAVE BEEN PORTRAYED IN CONTEMPORARY POETRY AND NARRATIVE.

PALAVRAS-CHAVE: ZOOLITERATURA - BESTIÁRIOS - LITERATURA CONTEMPORÂNEA KEY-WORDS: ZOOLITERATURE - BESTIARIES - CONTEMPORARY LITERATURE 
reciso sentir de novo o it dos animais.

Clarice Lispector

Jorge Luis Borges, no prólogo de seu Manual de zoologia, de 1957, começa por se referir à primeira visita de uma criança a um jardim zoológico e seu inevitável assombro diante da "desatinada variedade do reino animal" (BORGES e GUERRERO, 2003: 7-9). Após considerar que o contato prévio com um tigre de pano e com figuras de tigre em uma enciclopédia preparou essa criança para ver sem horror um tigre de carne e osso, Borges conclui - por vias transversas - que existem dois tipos de zoológico: o da realidade, povoado de animais existentes, e o das mitologias, que abriga esfinges, grifos e centauros, dentre outros monstros. O primeiro corresponderia ao que chama de "zoologia de Deus", e o segundo, à "zoologia dos sonhos".

Não obstante argumente que, ao contrário do que se pensa, o segundo zoológico é mais pobre que o primeiro, o escritor opta pelos animais teratológicos para construir sua coleção poético-descritiva ${ }^{1}$, retomando, dessa forma, a antiga tradição dos bestiários. Mas longe de apenas construir catálogo fixo e erudito de seres imaginários, à feição das coleções medievais, Borges, "mais atento às variantes", como observou Sylvia Molloy, "resgata do esquecimento monstros ilustres, reescreve-os a partir de nosso presente, dotando-os de uma nova e frágil vida, a do tempo de nossa leitura" (MOLLOY, 1999: 239). Ele evidencia, por esse viés, que a literatura não deixa de ser "uma monstruosa série de imaginações", além de revelar ironicamente os limites dos relatos enciclopédicos enquanto tentativas de mapeamento exaustivo da complexa e inesgotável variedade do mundo animal. Nesse sentido, os verbetes zoológicos de Borges, ao mesmo tempo em que advêm da literatura de séculos passados, convertem-se em textos precursores para toda uma nova tradição poética de bestiários fantásticos, surgida no contexto latino-americano da segunda metade do século XX.

Tal tradição inclui poetas de várias nacionalidades no âmbito da América Latina. Dentre eles, destacam-se o mexicano Juan José Arreola, o guatemal-

\footnotetext{
1 Ampliado consideravelmente em 1967, o Manual de zoología fantástica passou a se intitular El libro de los seres imaginarios, sendo acrescentados outros seres não-animais, como os elfos, os gnomos, as fadas e os anjos, e eliminada a ordem alfabética dos verbetes da edição anterior.
} 
teco Augusto Monterroso e o brasileiro Wilson Bueno ${ }^{2}$. Todos tomam como referência obrigatória para seus trabalhos a obra de Borges, mas com propostas distintas, seja por mesclarem a "zoologia dos sonhos" com a da realidade, seja por explorarem as metamorfoses - estas deliberadamente excluídas do Manual de zoologia fantástica -, seja por incorporarem explicitamente referências culturais latino-americanas em seus verbetes, estes feitos da mistura de poema, narrativa e descrição.

Em La oveja negra y demás fábulas (1969), por exemplo, Augusto Monterroso vale-se do tom de fábula para compor pequenos relatos descritivos, de feição poética, sobre animais reais e imaginários, instaurando - por meio do amálgama lirismo-ironia - uma zoopoética singular, a qual já foi definida por Carlos Fuentes como "o fantástico bestiário de Borges tomando chá com Alice" mesmo tempo em que recicla Esopo e La Fontaine, Monterroso dialoga com textos zoológicos do século XX, em especial os de Franz Kafka, compondo um bestiário politizado, cheio de indagações de ordem ética e atravessado de procedimentos narrativo-poéticos ousados e inventivos. Sua afinidade com a zooliteratura kafkiana é explícita e se dá a ver em vários textos, como em "La cucaracha soñadora", que aqui transcrevo:

\author{
Era una \\ vez una cucaracha \\ llamada Gregorio \\ Samsa que soñaba \\ que era una \\ Cucaracha llamada \\ Franz Kakfa que \\ soñaba que era un \\ escritor que
}

\footnotetext{
2 De Juan José Arreola: Bestiario - varia invención e Confabulario; de Augusto Monterroso: La oveja negra y demás fábulas; de Wilson Bueno: Jardim Zoológico e Manual de roofilia.

3 Isso foi dito por Fuentes na ocasião do lançamento da tradução de Oveja negra para o inglês. Cito o dizer completo: "Imagine el fantástico bestiario de Borges tomando el té con Alicia. Imagine a Jonathan Swift y James Thurber intercambiando notas. Imagine una rana del condado de Calaveras que hubiera leído realmente a Mark Twain. Conozca a Monterroso". Cf. http://cvc.cervantes.es/actcult/monterroso/cronologia/1957_1972.htm
} 


\author{
escribía acerca de \\ un empleado \\ llamado Gregorio \\ Samsa que soñaba \\ que era una \\ Cucaracha \\ (MONTERROSO, 1996: 45)
}

Juan José Arreola, por sua vez, elege para seu repertório apenas animais existentes (ele diz visitar "seus" animais no Zoológico de Chapultepec), mas inserindo-os numa realidade absurda do nosso tempo presente, também à feição de Kafka. Apresentando, por meio de uma escrita ágil e concisa, uma visão corrosiva da humanidade - para ele, "nós pertencemos a uma triste espécie de insetos" -, o escritor cria uma taxonomia própria para classificar os animais de seu catálogo, segundo traços do comportamento humano. Tudo isso dentro de um texto que, por se constituir de vários gêneros - do poema à narrativa e ao aforismo -, mereceu a designação de "varia invención", ou seja, uma espécie de criação literária que se furta aos gêneros canônicos para se afirmar como construto híbrido e sempre em estado de novidade. A propósito dessa mesclagem prosa-poesia, que não deixa de ser um dos traços constitutivos de praticamente todos os bestiários contemporâneos, o próprio Arreola afirmou: "Dentro de las limitaciones de la prosa brotó de pronto la poesía. [...] No quiero contar historias. Y el poema en prosa es una solución magnífica. Y cada vez se reduce más el poema en prosa que escribo" (ARREOLA, apud VÁSQUEZ, 2007).

Octavio Paz, na antologia Poesía en movimiento, também chama a atenção para essas mesclas de gênero na obra de Arreola, além de marcar o amálgama fantasia-humor como uma das linhas de força do texto do escritor, ao qual ainda atribui "el elemento explosivo: lo inesperado" (PAZ, 1994: 127). Aliás, esse caráter inesperado, insólito, do bestiário de Arreola se manifesta não apenas na linguagem e nas alegorias críticas que o poeta constrói, mas também nas associações que estabelece entre um animal e outros, como no verbete da zebra: "La cebra toma en serio su vistosa apariencia, e al saberse rayada se entigrece" (ARREOLA, 1997: 95). O que o coloca em sintonia com Monterroso, quando este conta a história de uma mosca que sonhava ser uma águia e que depois, 
em vigília, "lamentaba con toda el alma ser un Águila para remontar montañas, y se sentía tristísima de ser una Mosca” (MONTERROSO, 1996: 17).

Já no caso dos bestiários do paranaense Wilson Bueno, especialmente no livro Jardim Zoológico (1999), o caráter fantástico é mais ostensivo, uma vez que seus bichos são um compósito de elementos mitológicos, lendas indígenas, referências culturais brasileiras e hispano-americanas. Híbridos, fronteiriços, os bichos de Bueno são marcados pelos cruzamentos transnacionais advindos do contato entre os países do continente sul-americano. Além disso, são dotados de uma espécie de saber poético sobre a vida humana e sobre o próprio território que habitam, amalgamando características animais, humanas e divinas. Do híbrido Ivitu, por exemplo, "um pequeno deus de quatro patas", capaz de "mitigar, dos índios, a dor da saudade", passando pelos dúbios "êulikes" e os oblíquos "nuncas", até os "hesatís", que, "em tudo semelhantes a um pequeno elefante, não possuem, contudo, deste, a característica da tromba, mas uma pequena boca de lábios quase humanos" (BUENO, 1999: 11), os animais de Bueno reatualizam, por uma perspectiva transcultural, tanto os bestiários da tradição ibérica quanto as coleções zoológicas de Borges e as lendas indígenas brasileiras. ${ }^{4}$

Essa interseção de bestiários do passado e do presente leva-nos, inevitavelmente, a pensar em várias questões de ordem estético-cultural: em que medida as figurações zoológicas do presente revêem criticamente as imagens construídas pelos primeiros colonizadores em torno da América Latina? Até que ponto, ao retomarem procedimentos taxonômicos anteriores ao triunfo do racionalismo científico, esses poetas estariam proclamando, pelas vias oblíquas da ironia, a falência dos sistemas modernos de classificação e de conhecimento? Estariam esses zoopoetas contemporâneos assinalando, pelo viés metafórico, o caráter heterogêneo e inclassificável da tão buscada - e cada vez mais complexa - "identidade latino-americana"?

Sabemos que o que sustentou as imagens zoológicas do passado foi o assombro diante da diferença, da alteridade radical representada pelos bichos. Ou seja, dentro da perspectiva renascentista dos cronistas europeus, a diferença inscrevia-se na ordem do excêntrico, visto que o saber do tempo estava circunscrito à medida do Mesmo, como bem problematizou Michel Foucault,

4 Um estudo sobre Wilson Bueno e a zoologia fantástica latino-americana pode ser lido em MACIEL, M. E., A memória das coisas, p. 49-57. 
em As palavras e as coisas (FOUCAULT, 1987, p. 48). Daí que o outro, o estranho, se afigurasse como o monstruoso, como aquilo que deveria ser colocado no plano do exótico, do fantástico, ou ainda como aquilo que deveria ser subtraído de sua estranheza ameaçadora, domesticado pela força da "mesmidade" que, no caso específico do processo de colonização, era representada pela cultura canônica européia.

Por outro lado, o olhar contemporâneo dos poetas latino-americanos que retomam as imagens heteróclitas criadas em torno da fauna do continente vem esvaziar o caráter exótico dessas mesmas imagens, fazendo da diferença o traço constitutivo de uma identidade disforme, heterogênea e paradoxal. Esse olhar flagra na estranheza antes assombrosa dos monstros latino-americanos o elemento familiar, num reconhecimento do que foi recalcado pelo processo de colonização ao longo de todos esses séculos.

É precisamente considerando isso que se pode dizer, à feição de Octavio Paz, que nós, latino-americanos, somos e não somos Ocidente, visto que a ocidentalidade da América Latina não se define senão pela via do paradoxo. Somos ocidentais, pela força da geografia, das cartografias, das caravelas, de todos os artifícios da colonização e da modernização. Não o somos, porque nosso lugar na história cultural do Ocidente inscreve-se nas margens e nos desvãos dessa mesma história, está dentro e fora do mapa que nos circunscreve. Quando Foucault, no famoso prefácio de As palavras e as coisas, reporta-se à "monstruosidade que Borges faz circular em sua enumeração" (FOUCAULT, 1987: 6) dos animais da enciclopédia chinesa, ele traz à tona - movido pelo assombro que a lista zoológica de Borges lhe provoca - esse espaço paradoxal que não deixa de apontar também a própria realidade heterotópica do continente latino-americano. Um espaço onde sempre se inscreve o que Paz chamou de exercício de "otredad", ou seja, o reconhecer-se sempre outro, sem deixar de ser o mesmo ${ }^{5}$.

\footnotetext{
5 Silviano Santiago, no ensaio intitulado "A hora do lobisomem", também trata dessa questão, definindo, na linha de Paz, a América Latina como "o outro do Ocidente-dentro-do-Oriente". Ele afirma que "nossos autores sempre souberam integrar num solo único os dois ferozes inimigos inventados pelo etnocentrismo: o Mesmo e o Outro". E completa: "leitões, sereias, cães em liberdade e animais pertencentes ao imperador ou desenhados com um pincel muito fino de pêlo de camelo, esses seres heteróclitos sempre conviveram familiarmente no mesmo espaço enciclopédico latino-americano". E é nesse sentido que a China de Borges é aqui (cf. MACIEL, 2004: 55).
} 
Assim, ao subtraírem dos bichos estranhos o traço de exotismo e deles criarem metáforas de uma identidade cultural híbrida, em estado de deslocamento, tais escritores assumem, como marca de sua própria subjetividade, uma espécie de razão animal. Dessa razão extraem um saber que tem no corpo a sua expressão mais viva e um olhar que traz, ao mesmo tempo, todos os afetos e sentidos. Não por acaso, os pequenos "giromas" do jardim zoológico de Wilson Bueno têm dezenas de olhos, sendo que estes também servem para escutar, aspirar o ar e excretar a chuva que bebem, fertilizar-se; e os jaquapitãs, animais caninos de cor vermelha, "possuem olhos de ouro raiados de sangue, e é como se coubesse neles uma impossível paisagem" (BUENO, 1999: 26). Pode-se dizer que o sujeito que os descreve está irremediavelmente contagiado por esse saber, e assume tal contágio como uma espécie de devir para sua própria humanidade/animalidade, mantendo com os animais uma relação da ordem do pacto. Por meio deles, rastreia o território mestiço da América Latina, as fronteiras, as zonas subterrâneas, reconfigurando, nos planos geográfico, cultural e textual, o espaço enciclopédico do continente.

Vale ainda acrescentar que, nesses textos de Bueno, o aspecto fantástico não exclui o espaço dos animais existentes, mas, sim, o potencializa. E isso se dá de forma mais intensa em Manual de zoofilia (1997), em que o autor busca explorar a passagem das fronteiras entre o humano e o inumano, num processo de identificação do sujeito poético com esse completamente outro que é o animal. No livro, borboletas, pardais, lobos, andorinhas, gatos, cadelas, raposas e colibris compõem um conjunto vivo de criaturas dotadas de subjetividade, com quem o escritor mantém uma instigante relação de cumplicidade e de devir. Tomando, por vias transversas, a assertiva de Deleuze e Guattari de que "todo animal é antes um bando, uma matilha" (DELEUZE \& GUATTARI, 1997: 20) e, ao mesmo tempo, afirmando a singularidade subjetiva de cada bicho, Bueno descreve, por exemplo, o estado de abandono de um lobo excluído de seu grupo. Cito um fragmento: "Há o desamparo recurvo do lobo se o líder da alcatéia o expulsa, além-matilha. É um animal quebrado sem o seu bando. Não se fie contudo em seus caninos. Moram neles, nos lobos, os acidentes da fome e os do pânico" (BUENO, 1997: 35).

Vê-se que o poeta se coloca na "hora do mundo" desse lobo desgarrado e, pela força da expressão poética, a ele confere uma complexa existência, com a qual parece compactuar o tempo todo. 
Pode-se dizer, por fim, que tanto Borges quanto Arreola, Monterroso e Bueno revisitam, subvertem, parodiam e desestabilizam todo um repertório de imagens, textos e saberes zoológicos do passado ocidental. Seus bestiários, longe de serem meras restaurações eruditas do gênero, colocam-se também como espaços de reflexão crítica sobre aspectos literários, culturais e políticos dos modelos anteriores. Das enciclopédias antigas, passando pelas crônicas de viagem do mundo renascentista, pelo naturalismo de Aldrovandi, pelas classificações científicas de Lineu, até o surgimento, na modernidade do século XIX, das chamadas ciências da vida, esses autores buscam converter tudo - através do prisma de um olhar atualizado - em matéria-prima para seus escritos.

Eles abrem, dessa forma, um campo fértil para os poetas do novo milênio, que, agora, têm a tarefa de repensar a questão dos animais sob o ponto de vista da lamentável situação ecológica do mundo. Cabe aos "zoopoetas" do presente assumir a responsabilidade ética e estética de escrever sob o impacto da certeza de que vivemos, hoje, num tempo em que as espécies entraram em estado de irremediável extinção, tempo em que uma reflexão incisiva sobre as práticas de assujeitamento e crueldade contra os animais torna-se cada vez mais necessária e urgente no mundo contemporâneo.

\section{Referências Bibliográficas}

ARREOLA, Juan José. Bestiário - varia invención. Madrid: Turner, 2002. . Confabulario. México: Fondo de Cultura Económica, 2002.

BORGES, Jorge Luis; GUERRERO, Margarita. El libro de los seres imaginarios. Madrid: Alianza Editorial, 2003. 1998. Manual de zoología fantástica. México: Fondo de Cultura Económica,

BUENO, Wilson. Jardim Zoológico. São Paulo: Iluminuras, 1999. . Manual de zoofilia. Ponta Grossa: UEPG, 1997.

CENTRO VIRTUAL CERVANTES. Augusto Monterroso - cronologia. Disponível em: <http://cvc.cervantes.es/actcult/monterroso/cronologia/1957_1972.htm>. Acesso em: 18 nov. 2007.

DELEUZE, Gilles; GUATTARI, Félix. Devir-intenso, devir-animal, devir-imperceptível. Trad. Suely Rolnik. Mil platôs - capitalismo e esquizofrenia. Rio de Janeiro: Ed. 34, 1995. v. 4. 
DERRIDA, Jacques. O animal que logo sou. Trad. Fábio Landa. São Paulo: Ed. Unesp, 2002.

FOUCAULT, Michel. As palavras e as coisas. Trad. Salma Tannus. São Paulo: Martins Fontes, 1987.

MACIEL, Maria Esther. A memória das coisas: ensaios de literatura, cinema e artes plásticas. Rio de Janeiro: Lamparina, 2004.

MOLLOY, Silvia. Las letras de Borges y otros ensayos. Rosario: Beatriz Viterbo, 1999.

MONTERROSO, Augusto. La oveja negra y demás fábulas. México: Fondo de Cultura Económica, 1996.

PAZ, Octavio. Poesía en movimiento. In: Generaciones y semblanzas. Dominio mexicano. Obras completas. México: Fondo de Cultura Económica, 1994. t. 4, p. 127.

SANTIAGO, Silviano. A ameaça do lobisomem. Revista Brasileira de Literatura Comparada, Florianópolis, p. 31-44, 1998.

VÁZQUEZ, Felipe. Juan José Arreola y el género "varia invención”. Espéculo. Revista de estudios literarios. Universidad Complutense de Madrid. Madrid, n. 32. Disponível em: <http://www.ucm.es/info/especulo/numero32/arreola.html>. Acesso em: 18 nov. 2007. 